\section{A FORTRAN IV program for linear contrasts in designs with repeated measurements}

\section{JON WRIGHT and DAVID M. LANE Rice University, Houston, Texas 77001}

In addition to an overall analysis of variance, it is often desirable to test specific contrasts among means. Although the calculations necessary to test a linear contrast in a between-groups design are simple enough to be done with a hand calculator, they are lengthy and cumbersome in designs with repeated measurements; in those designs a different error term must be calculated for each contrast. The program described here enables one to test contrasts for designs with repeated measurements on one or more factors.

Input. The first card following the title card must contain the number of subjects per group, the number of groups in the design, the number of scores obtained from each subject, and the number of coefficient sets to be tested. The variable format card and the raw data follow. The user has the option of inputting the covariance matrix and cell means in place of raw data. Finally, the within-subjects contrasts are input. Specific instructions on card preparation are provided on comment cards.

Output. The within-groups covariance matrix is printed, and optionally, punched on cards. In the case of unequal group size, the harmonic $n$ is reported. For each contrast, the program prints (1) normalized coefficients, (2) a vector of group means calculated by applying the normalized coefficients to the groups by measurements cell means, (3) the mean square error for the contrast, (4) an F test for the contrast, and (5) an $F$ test for the Groups by Contrast interaction. The user may wish to break down the Groups by Contrast interaction into individual components. This can be easily accomplished with a hand calculator; computational procedures and an example are shown in the Appendix.

Limitations. The program can analyze data from any repeated-measures design. Unweighted means analysis is used if the group sizes are unequal. Presently, the program allows a maximum of 30 repeated measurements and 50 groups. These limits can easily be extended by changing the dimension statements in the program.

Computer and Language. The program is written in FORTRAN IV and was developed on an IBM 370 computer. It should run with little or no modification on any computer system with a FORTRAN compiler.

Core and Time Requirements. The program has 197 statements aside from the comment cards and takes up $34 \mathrm{~K}$ bytes in core. An additional $34 \mathrm{~K}$ are used for data storage. The program executes relatively quickly: It takes $1.35 \mathrm{sec}$ on our system to analyze the nine orthogonal contrasts resulting from a design with three
Table 1

Group Means on the $\mathrm{C}_{\text {linear }}$ Contrast and the Analysis of Variance Summary Table

\begin{tabular}{cclrrrr}
\hline Group & Means & \multicolumn{1}{c}{ Source } & \multicolumn{1}{c}{ SS } & df & \multicolumn{1}{c}{ MS } & \multicolumn{1}{c}{ F } \\
\hline A1B1 & 4.6957 & Contrast & 570.42 & 1 & 570.42 & 221.52 \\
A1B2 & 7.2300 & Groups by Contrast & 25.68 & 3 & 8.56 & 3.32 \\
A2B1 & 6.8573 & Error & 20.60 & 8 & 2.58 & \\
A2B2 & 8.7952 & & & & &
\end{tabular}

groups, 20 subjects per group, and 10 measurements per subject.

Availability. A listing of the program and instructions on its use can be obtained at no cost by writing to David M. Lane, Department of Psychology, Rice University, Houston, Texas 77001 .

\section{Appendix \\ Computational Procedures for Designs with Two or More Between-Groups Variables}

Consider as an example the following three-factor mixed design taken from Winer $(1971$, p. 584). There are two levels of A, two levels of B, and four levels of $C$, the within-subjects factor. If one were interested in testing the effects of a linear trend over $\mathrm{C}$ and interactions with this component, the linear trend coefficients $-3,-1,1$, and 3 would be input. The program would normalize the coefficients $-.6708,-.2236, .2236$, and .6708 and report the ANOVA summary and the group means for the normalized coefficients as in Table 1.

The group by contrast sums of squares contains variation due to the $\mathrm{AXC}_{\text {linear }}, \mathrm{BXC}_{\text {linear }}, \mathrm{AXBXC}$ linear interactions. To partition this source of variation, the user must make up contrasts representing the effects of $A, B$, and the $A X B$ interaction. The application of these contrasts to the group means on the $\mathrm{C}_{\text {linear contrast results in the appropriate partitioning }}$ of the Group by Contrast interaction. To compute the sums of squares for a contrast, the following formula is appropriate: $\mathrm{SS}=\mathrm{n}\left(\mathrm{c}_{1} \overline{\mathrm{T}}_{1}+\mathrm{c}_{2} \overline{\mathrm{T}}_{2}+\ldots+\mathrm{c}_{\mathrm{k}} \overline{\mathrm{T}}_{\mathrm{k}}\right)^{2} / \Sigma \mathrm{c}^{2}$, where $\overline{\mathrm{T}}_{\mathrm{i}}$ is the mean of the ith group, $c_{i}$ is the ith coefficient, and $n$ is the number of subjects per group. If the group sizes are unequal, the harmonic $n$ should be used in place of $n$. For the present example, $\mathrm{n}=3$, and therefore,

$\mathrm{SS}\left(\mathrm{AXC}_{\mathrm{lin}}\right)$

$=\frac{3[(-1)(4.6957)+(-1)(7.23)+(1)(6.8573)+(1)(8.7952)]^{2}}{\left[(-1)^{2}+(-1)^{2}+(1)^{2}+(1)^{2}\right]}$

$=10.42$

$\mathrm{SS}\left(\mathrm{B} \times \mathrm{C}_{\text {lin }}\right)$

$=\frac{3[(1)(4.6957)+(-1)(7.23)+(1)(6.8573)+(-1)(8.7952)]^{2}}{\left[(1)^{2}+(-1)^{2}+(1)^{2}+(-1)^{2}\right]}$

$=15.0$

$\mathrm{SS}\left(\mathrm{A} \times \mathrm{B} \times \mathrm{C}_{\mathrm{lin}}\right)$

$=\frac{3[(-1)(4.6957)+(1)(7.23)+(1)(6.8573)+(-1)(8.7952)]^{2}}{\left[(-1)^{2}+(1)^{2}+(1)^{2}+(-1)^{2}\right]}$

$=.267$. 


\section{WRIGHT AND LANE}

The reader is referred to Kerlinger and Pedhazur (1973, p. 131) for information on the construction of orthogonal contrasts.

\section{REFERENCES}

Kerlinger, F. N., \& Pedhazur, E. J. Multiple regression in behavioral research. New York: Holt, Rinehart, \& Winston, 1973.

WINER, B. J. Statistical principles in experimental design (2nd ed). New York: McGraw-Hill, 1971.

(Accepted for publication February 28, 1978.) 